Article

\title{
Applicability of Swaging as an Alternative for the Fabrication of Accident-Tolerant Fuel Cladding
}

\author{
Dae Yun Kim ${ }^{1}$, You Na Lee ${ }^{1}$, Joon Han Kim ${ }^{2}$, Yonghee Kim ${ }^{3, *}$ and Young Soo Yoon ${ }^{1, *}$ \\ 1 Department of Materials Science and Engineering, Gachon University, Gyeonggi-do 13120, Korea; \\ ct1352@gc.gachon.ac.kr (D.Y.K.); ynl87@gc.gachon.ac.kr (Y.N.L.) \\ 2 SFR Nuclear Fuel Development Division, Korea Atomic Energy Research Institute, Daejeon 34507, Korea; \\ junhkim@kaeri.re.kr \\ 3 Department of Nuclear and Quantum Engineering, Korea Advanced Institute of Science and Technology, \\ Daejeon 34141, Korea \\ * Correspondence: yongheekim@kaist.ac.kr (Y.K.); benedicto@gachon.ac.kr (Y.S.Y.)
}

Received: 25 May 2020; Accepted: 17 June 2020; Published: 19 June 2020

\begin{abstract}
We suggest an alternative to conventional coating methods for accident-tolerant fuel (ATF) cladding. A Zircaloy-4 tube was inserted into metal tubes of different materials and the inserted tubes were subjected to physical force at room temperature. The manufactured tube exhibited a pseudo-single tube (PST) structure and had higher thermal stability than a Zircaloy-4 tube. Optical microscopy and scanning electron microscopy images showed that the PST had a uniform and well-bonded interface structure, i.e., no gaps or voids were found at the interface between the inner and outer tubes. Energy-dispersive $\mathrm{X}$-ray spectroscopy analysis confirmed that the metal components did not interdiffuse at the interface of the PST, even after being kept at 600 and $900{ }^{\circ} \mathrm{C}$ for $1 \mathrm{~h}$ and rapidly cooled to room temperature. Unlike pure Zircaloy-4 tubes, Zircaloy-4/stainless use steel (SUS) 316 PST did not show significant structural collapse, even after being stored at $1200{ }^{\circ} \mathrm{C}$ for $1 \mathrm{~h}$. Based on these results, if a PST was fabricated using a Zircaloy- 4 tube thinner than the Zircaloy- 4 tube used in this study and an outer tube of micron-scale thickness, swaging may be a feasible alternative to Zircaloy-4-based ATF cladding.
\end{abstract}

Keywords: alternative process; non-coating method; room-temperature swaging; pseudo-single tube (PST); accident-tolerant fuel (ATF) cladding

\section{Introduction}

Nuclear fuel claddings are crucial core materials in nuclear power plants. They effectively transfer the heat generated by the fission reaction to the coolant, while preventing the fuel and fission products from leaking into the coolant. Therefore, selecting cladding materials with high corrosion resistance, suitable mechanical properties, and the ability to withstand high pressures, temperatures, and irradiation is vital. Zirconium alloys have shown high potential as cladding materials, owing to their low neutron absorption rate, high corrosion resistance, and stable mechanical properties under the operating conditions of the reactor [1-4]. However, zirconium alloys were found to lack sufficient physical and chemical stability in the Fukushima nuclear power plant accident, highlighting the necessity for research on the development of accident-tolerant fuel (ATF) claddings with improved physicochemical stability. Several alternative ATF claddings have been developed in and outside of Korea, including the M5 physical vapor deposition (PVD)-coated cladding by AREVA [5], the Fe-Cr-Al alloy by ORNL [6], the SiC/SiCf composite by MIT [7], and the Cr laser coating by KAERI [8,9]. However, the ATF cladding fabrication techniques described above have the following disadvantages: it is difficult to achieve uniform surface modifications, such as coatings, on long fuel rods, and issues 
such as peeling can occur due to thermal shock [10]; FeCrAl alloys experience neutron absorption and tritium emission problems [11]; $\mathrm{SiC} / \mathrm{SiC}_{\mathrm{f}}$ composite claddings consist of ceramics and are therefore exceedingly unstable in terms of fatigue behavior; and, finally, the abovementioned claddings are difficult to mass-produce, and also incur high production costs $[12,13]$. To overcome these shortcomings, we propose swaging as an alternative method for the production of ATF claddings. Swaging is a simple process and can be carried out at room temperature. In general, the term "swaging" refers to the process of creating a tube with an outer diameter of a desired size by applying a physical force toward the center of a tube with a larger outer diameter. In this study, swaging indicates the process whereby a tube is inserted into another tube that has an inner diameter greater than the outer diameter of the inserted tube; subsequently, these tubes are joined by applying compressive and tensile stresses toward the center and along the lengths to form a pseudo-single tube (PST) without gaps. If a metal or alloy material with physicochemical properties suitable for nuclear power plant operations is produced in the form of a tube into which Zircaloy-4 can be inserted, there is a possibility that a PST of a length of several meters (more than $1 \mathrm{~m}$ ) can be easily manufactured using swaging. This process requires a $4 \mathrm{t} / \mathrm{cm}^{2}$ load rolling press, and the finished PST has an increased length and a reduced outer diameter compared with the starting tube. The entire swaging process is performed at room temperature; hence, there are no heat-induced formations of microstructures or phase deformations during the process. A heat treatment test confirmed that the interface of the PST remained thermally stable at high temperatures. Furthermore, with swaging, surface modification is possible without length constraints and the results of heat treatment suggest that the PST is suitable for use as an ATF cladding [14-16]. The biggest advantage of swaging compared to the coating method is that uniform cladding can be manufactured in a short time at low cost. This advantage can be increased as the size of cladding increases, which leads to the expectation of mass productivity. The coating method may be more advantageous than swaging to set the optimum point of the cladding thickness but there may be many shortcomings in terms of practical use [17]. When cladding is formed over the entire area of a metric cylindrical tube, it is necessary to verify whether the optimal thickness can be formed uniformly. This is important because it is directly related to the safety of nuclear energy. The produced PSTs can also be applied in other industries in the form of metal tubes, which can be manufactured with the desired physical and chemical properties, depending on the choice of materials and the thickness of the outer and inner tubes.

Although in this study, a sample with an ATF geometry (cladding length and thickness) that is directly applicable to nuclear operations has not been used, a $90 \mathrm{~cm}$-long PST was constructed of stainless use steel (SUS) 316 (outside) and Zircaloy-4 (inside) and its high-temperature stability was confirmed. Based on this, we suggest that swaging can be an alternative process for the fabrication of ATF claddings. For this purpose, the interface between the two metals of a PST tube was analyzed before and after high-temperature heat treatment by optical microscopy (OM) and scanning electron microscopy (SEM). Furthermore, Zircaloy-4 cladding and Zircaloy- 4 with SUS 316 on the surface, i.e., PST, were exposed to high temperatures for the same durations and their physicochemical stabilities were compared. The core of this study is to suggest a simple and practical process method that can compensate for the disadvantages of the existing coating method. The most frequently mentioned cladding materials are $\mathrm{Cr}$ or $\mathrm{Cr}$-based alloys and studies to optimize them are still incomplete. For the swaging process, a cladding tube manufactured in the form of a pipe is required and the difficulty of its manufacture serves as a barrier to the progress of this study [18]. In this situation, we have conducted prior studies on the applicability of the swaging process for ATF cladding by focusing on the process method using SUS 316, which has excellent oxidation resistance, heat resistance, and workability and is readily available. Although SUS 316 is not the optimal material for ATF cladding, we think it is persuasive to use it to confirm the possibility of the swaging process. 


\section{Experimental}

\subsection{Swaging Method}

The inner tube comprised Zircaloy-4 (outer diameter: $9.57 \mathrm{~mm}$, inner diameter: $8.30 \mathrm{~mm}$, length: $1 \mathrm{~m}$ ) and the outer tube comprised SUS 316 (outer diameter: $11.90 \mathrm{~mm}$; inner diameter: $9.82 \mathrm{~mm}$; length: $1 \mathrm{~m})$. The surfaces of Zircaloy-4 and SUS 316 tubes were cleaned by wiping with ethanol. A double tube was prepared by inserting the Zircaloy-4 tube into the SUS 316 tube. The inner tube was completely filled with water-soluble $\mathrm{KNO}_{3}$ filler powder, so that the tube would not experience distortion during compression in the direction perpendicular to the tube surface and also so that the stress could be uniformly applied in all directions. The PST was synthesized by applying a pressure of $4 \mathrm{t} / \mathrm{cm}^{2}$ in the direction of the central axis of the double tube. Meanwhile, it was difficult to quantify the magnitude of the tensile stress in the transverse direction, which arose from the $4 \mathrm{t} / \mathrm{cm}^{2}$ compressive stress applied in the longitudinal direction. Each time the tube was passed through the shaft jig, the speed of the tube was manually controlled, so that the outer diameter of the outer tube was reduced by $0.5 \mathrm{~mm}$ of the total. Figure 1 shows a schematic of the swaging method for the double tube and the stress type applied to the tube during the process. Figure 2 shows that the inner surface of the outer tube and the outer surface of the inner tube adhere closely to each other. The compressive stress applied during swaging and the tensile force applied in the longitudinal direction result in a strong adhesive force. In addition, the thickness, inner and outer diameters, and length of the final tube can be adjusted, depending on the number of repetitions. The $\mathrm{KNO}_{3}$ left inside the PST was removed by immersing the PST in water at room temperature.

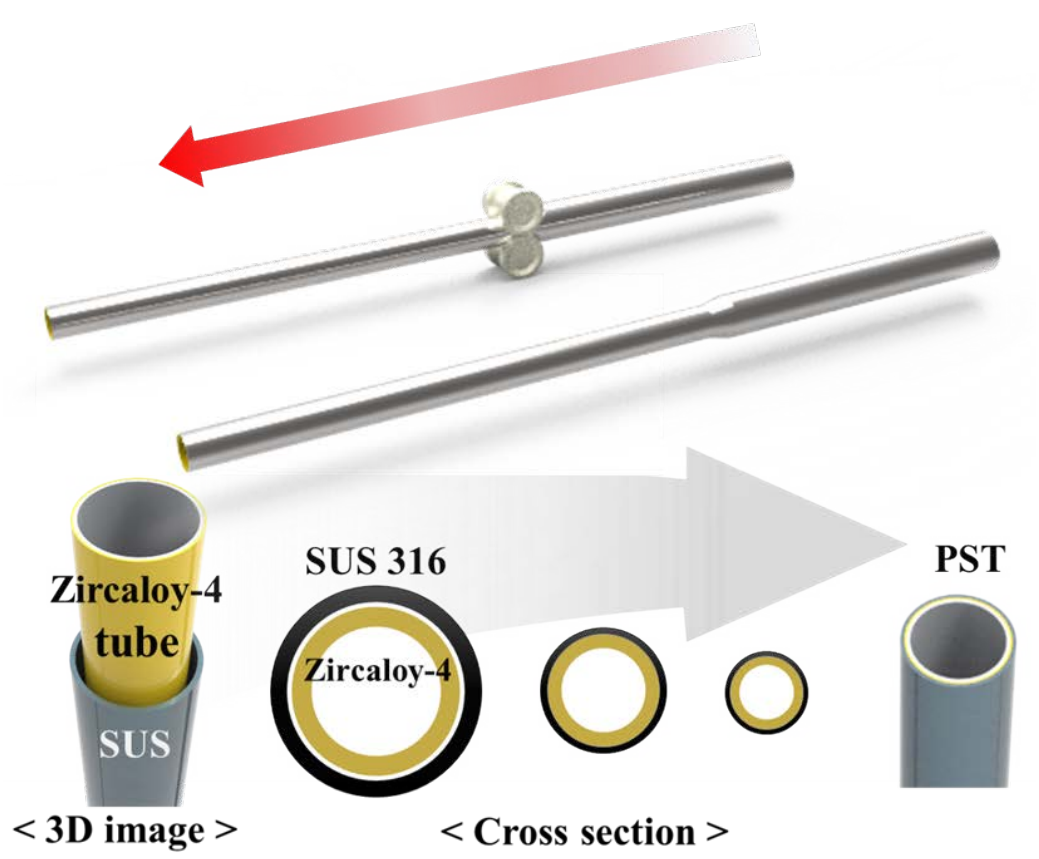

Figure 1. Schematic view of the swaging method for a double tube and the stress type applied to the tube during the process. 


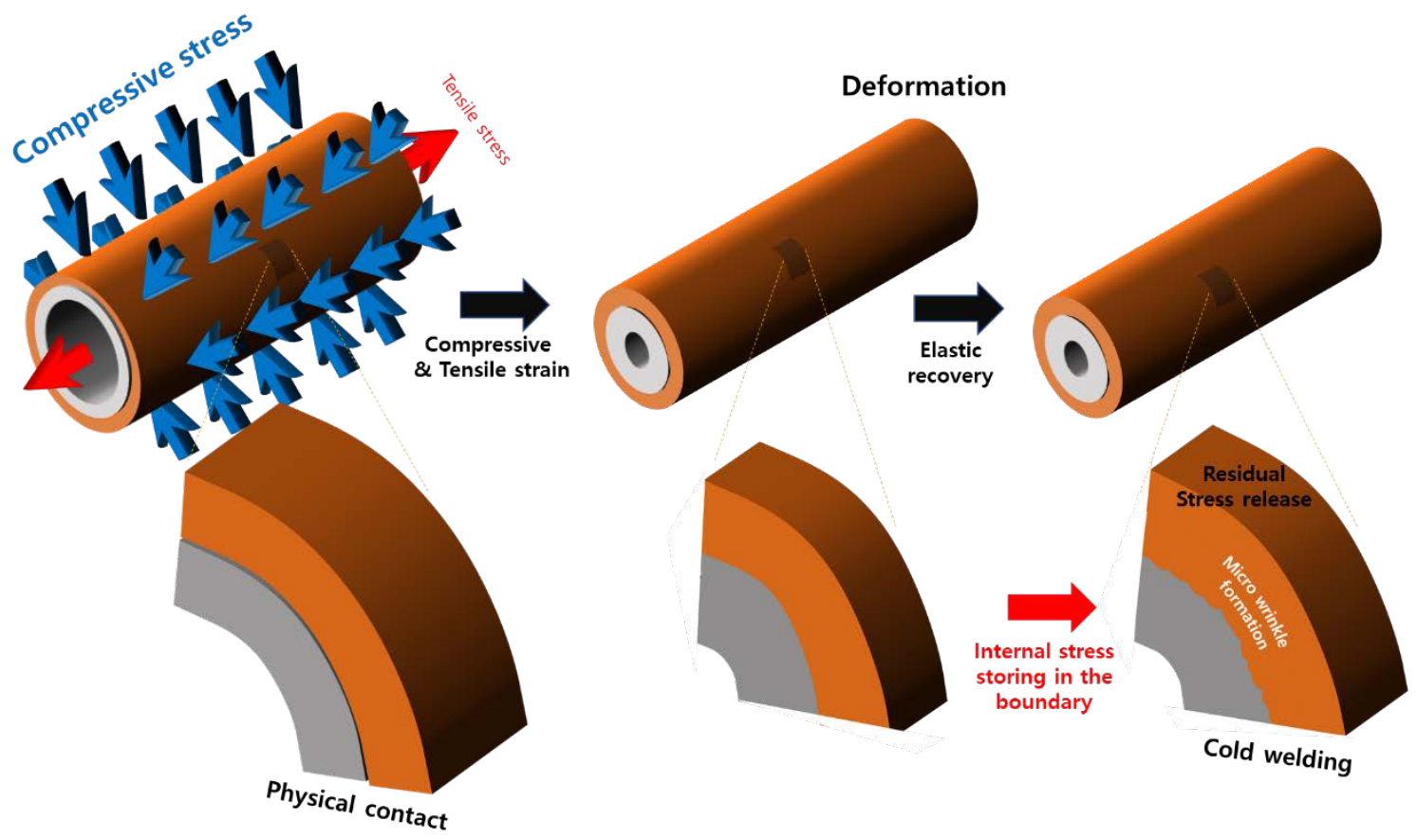

Figure 2. Mechanism of swaging.

\subsection{Heat Treatment}

Cut pieces of Zircaloy-4 cladding tubes and PSTs with a thickness of $2 \mathrm{~cm}$ were prepared and heat-treated in air under the following conditions: starting from room temperature $\left(0 \sim 25^{\circ} \mathrm{C}\right)$, after they had reached 600,900 , or $1200{ }^{\circ} \mathrm{C}$, at a rate of $100{ }^{\circ} \mathrm{C} / \mathrm{h}$, each tube was maintained at the specified temperature for $1 \mathrm{~h}$. The tubes were left to cool to $200{ }^{\circ} \mathrm{C}$ before being taken out of the furnace. Figure 3 shows a schematic of the heat treatment and the treatment conditions.

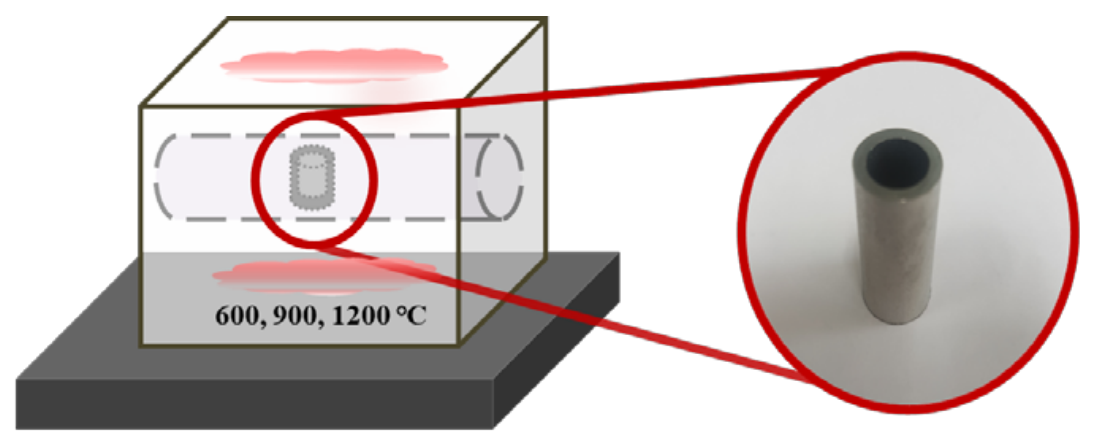

Multi-tube preparation by rolling press

\section{Sample cutting}

$(2 \mathrm{~cm})$

\section{SEM, EDS}

\section{heat treatment} $\left(600,900,1200{ }^{\circ} \mathrm{C}\right.$ for $\left.1 \mathrm{~h}\right)$

Figure 3. Schematic and conditions of heat treatment. 


\subsection{Analysis}

To compare the degrees of oxidation and the stability of the interfaces after exposure to high temperatures, $2 \mathrm{~cm}$-long tubes were prepared as follows: each tube was immersed in epoxy and dried until it solidified. Subsequently, the tubes immersed in the solidified epoxy were cut, their cross-sections were polished, and the microstructures of the polished surfaces were analyzed by OM. An SEM analysis was performed to examine the interfacial structure obtained from the $\mathrm{OM}$ at high resolution. EDS was used to analyze the diffusion behavior of the metal components at the PST interface after high-temperature heat treatment. In addition, because the two tubes were adhered solely by physical force, the cross-sections were analyzed using transmission electron microscopy (TEM) to confirm the characteristics of the interface at a higher resolution. The cross-sections of the PSTs were prepared for the TEM analysis by focused ion beam (FIB) milling.

\section{Results and Discussion}

Figure 4a shows the fabricated $90 \mathrm{~cm}$-long PST and Figure $4 \mathrm{~b}$ shows its cross-section before and after swaging. From Figure $4 \mathrm{~b}$ it can be seen that some $\mathrm{KNO}_{3}$ filler remained inside the tube with the smaller internal diameter after swaging, which could be easily removed with water. Figure 5 shows the OM image of three points on the interface of the PST. This image confirms that there were no gaps or voids in all three points of the interface between the two tubes, which was brought about by applying stress radially inward and lengthwise. Furthermore, the bonding interface between the two tubes was determined to be the same along the entire circumference. The uniformity of the interface of the PST was further confirmed by SEM images of the metal interface, as shown in Figure 6. It is imperative to note that gaps in the interface can degrade the mechanical and chemical properties of the tube. An interface without three-dimensional defects, such as gaps or voids, does not undergo oxidation reactions; therefore, it does not experience mechanical and chemical decomposition, even in high temperatures or corrosive environments [19]. As shown in Figure 6, the PST fabricated by swaging exhibits an exceedingly dense interface without three-dimensional defects.

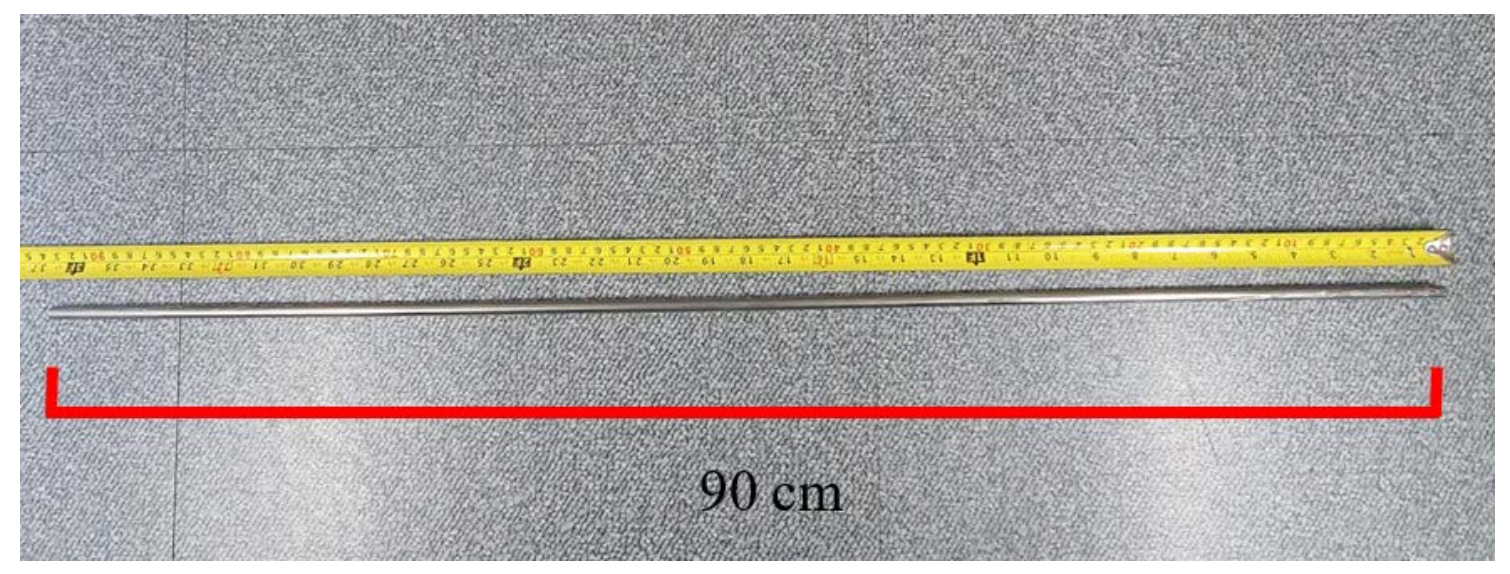

(a)

Figure 4. Cont. 


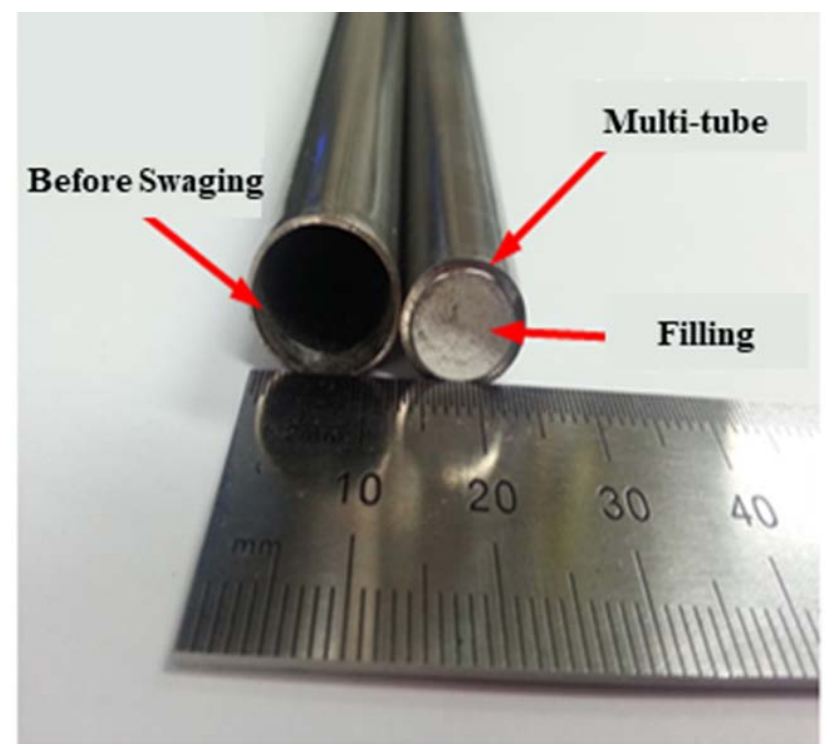

(b)

Figure 4. (a) Photographs of the final pseudo-single tube (PST), (b) Comparison of size change before and after swaging.

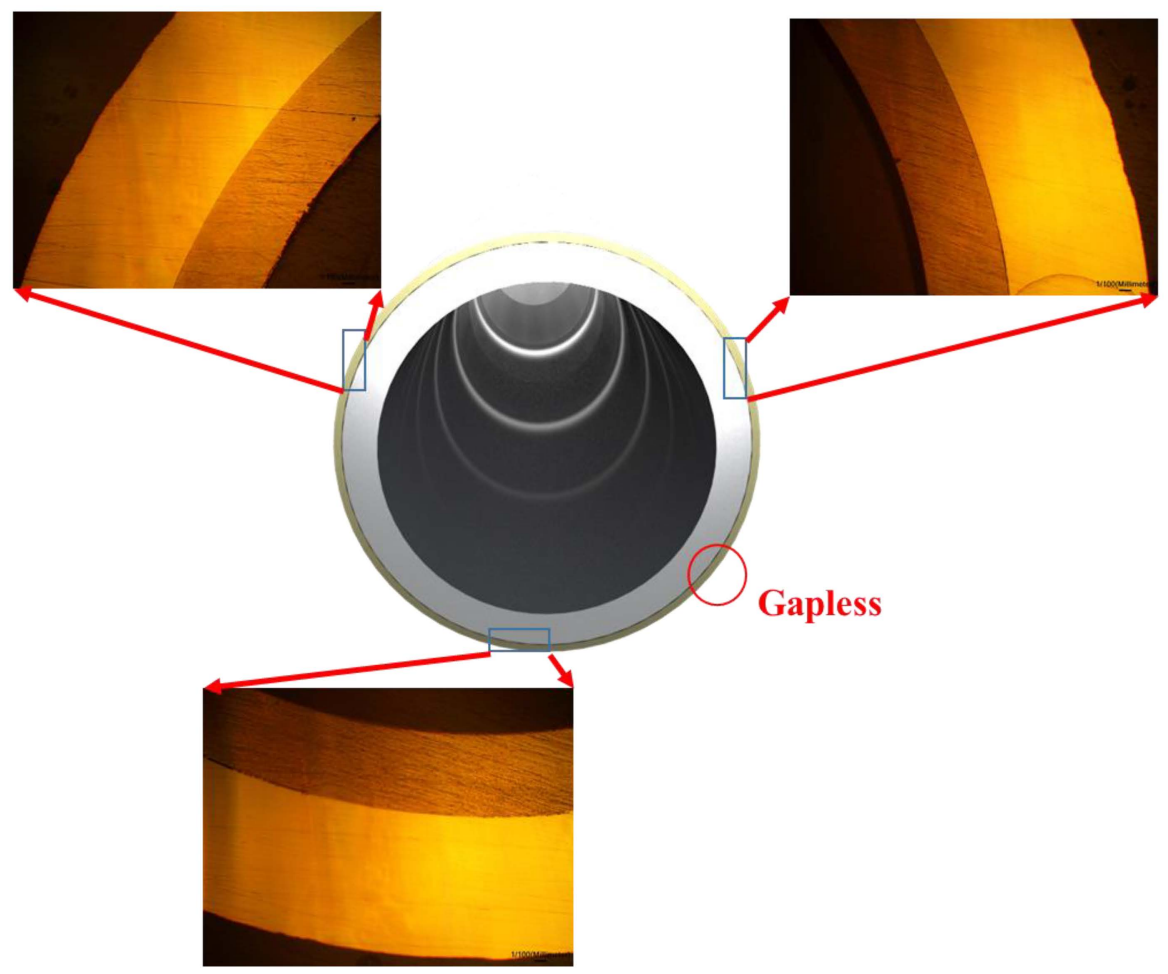

Figure 5. Optical microscopy image of PST without heat treatment. Schematic of the PST manufacturing process by swaging.

A peculiarity was that the tube thickness increased by approximately $5 \%$ from 3.35 to $3.52 \mathrm{~mm}$ after swaging, which can be explained as follows: during swaging, powder fillers were subjected to compressive stress in the direction of the center of the tube. Owing to plastic deformation, the inner diameter of the tube did not return to its original state, even after removal of the compressive stress [20]. During the initial stages of swaging, the tube length remained unchanged, thus increasing the tube thickness. 


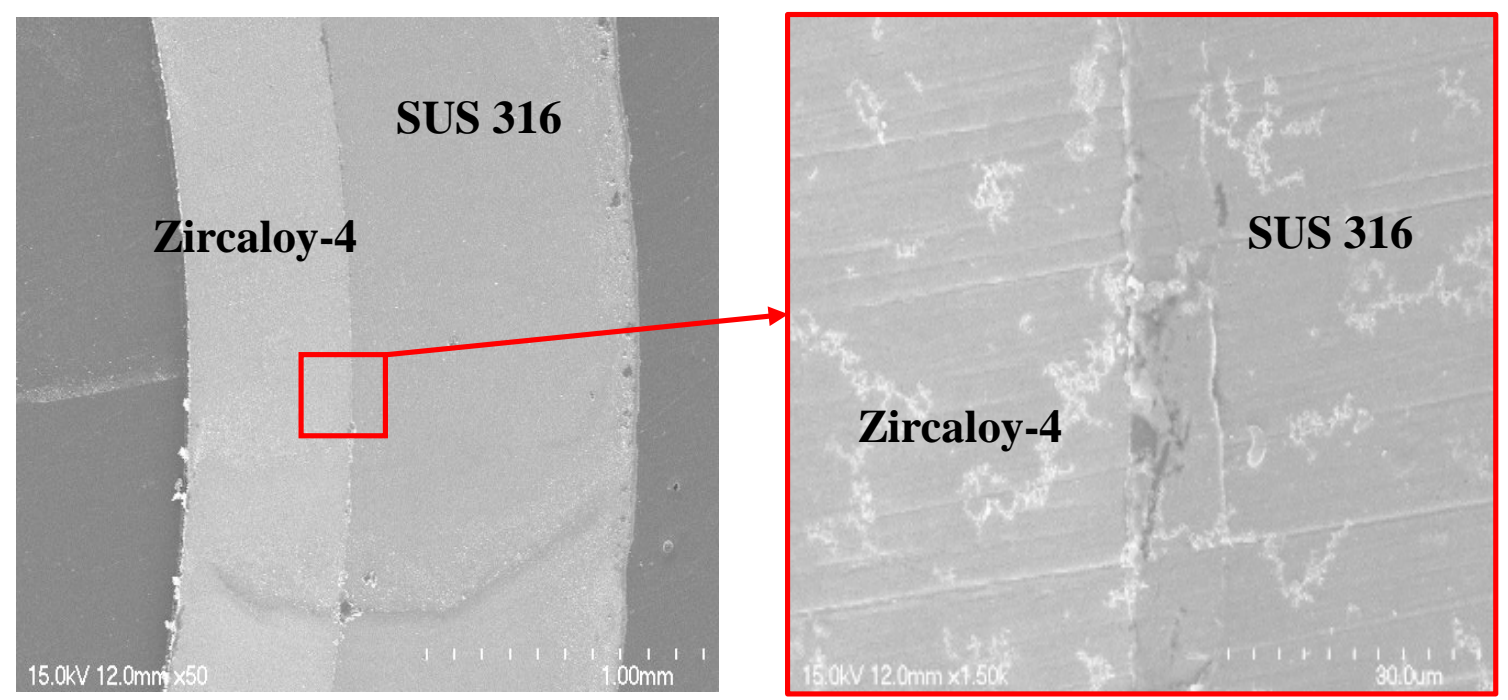

Figure 6. Secondary electron microscope image of the PST interface without heat treatment.

Once the filling powder entered a high-density state in which it could not be compressed further during swaging, the metal tube was also no longer compressed under external compressive stress. After this step, the tube started becoming longer and thinner due to the tensile stress applied to the tube. When using the swaging process, the magnitudes of the compressive stress acting perpendicular to the axial longitudinal direction and the tensile stress acting in the longitudinal direction were the most important variables for determining the length and thickness of the final PST. It is crucial to design a PST such that the initial sum of the thickness of each tube is as close as possible to the thickness of the single Zircaloy-4 tube currently in use. In particular, after completion of the process, the outer tube should ideally be suited to possess a thickness that modifies the chemical properties of the surface with little effect on the mechanical properties of the Zircaloy- 4 and the degree of neutron absorption. Therefore, it is preferable to start the process with an outer tube as thin as possible. However, as mentioned above, in this study, the swaging process was carried out using a commercially available thick SUS 316 tube for the purpose of proving that Zircaloy- 4 and dissimilar metals can be produced in the PST form using the described tube process. We are currently investigating the relationship between compressive stress and tube length and thickness.

At room temperature, the physical pressure applied toward the center of the tube and in the longitudinal direction of the two tubes leads to the formation of an interface with a strong bonding force. This can be explained by the mechanism, as illustrated in Figure 2. During swaging, the tube was subjected to compressive and tensile stresses in the axial and longitudinal directions. However, the tensile stress acting in the axial direction of the tube was not generated by the tube being pulled from the outside in the swaging equipment. This stress is thought to have been generated by the $\mathrm{KNO}_{3}$ filler pressing toward the center. Tensile stress occurred in the longitudinal direction of the tube, as the inner diameter of the tube decreased, when a force of $4 \mathrm{t} / \mathrm{cm}^{2}$ was applied to the center of the tube. This can be understood from the fact that the tube length increased after swaging, even if no tensile stress was applied. The most frequently mentioned cladding materials are $\mathrm{Cr}$ or $\mathrm{Cr}$-based alloys and studies to optimize them are still incomplete. Because of this, it is not yet possible to measure or calculate the exact magnitude of the tensile stress generated in the longitudinal direction by the reduction of the inner diameter of the tube with the equipment used in this study. Clearly, however, the most important variable in the shaft process is the control of the compressive stress applied in the direction of the center of the shaft. We are designing and manufacturing new tube equipment that can accurately measure and control the magnitude of the tensile stresses created in the longitudinal direction induced by compressive stresses, along with the values of the compressive stresses. 
Differences in physical properties, such as in the moduli of elasticity, shear moduli, and tensile strengths of the two metals after the tube process, result in different shrinkage behavior after stretching. Table 1 shows various physical properties of Zircaloy-4 and SUS 316. The total strain generated by swaging consists of a combination of elastic strain and plastic strain. An elastic deformation results in a return to the original state when the applied stress is removed; however, some permanent deformation, that is, plastic deformation, remained as the yield strength was exceeded. Finally, this plastic deformation resulted in a PST which is longer than the initial tube and has a smaller inner diameter than the initial tube [21]. As can be inferred from Table 1, Zircaloy-4 and SUS 316 tubes have different yield strengths, which can result in different final shrinkages. The first tube was $90 \mathrm{~cm}$ in length but post the tube process, the lengths of the Zircaloy-4 and SUS 316 tubes increased to 97.5 and $95.4 \mathrm{~cm}$, respectively. Table 2 shows the sizes of the tubes before and after swaging. It can be seen that the outer and inner diameters decrease after the shaft.

Table 1. Physical properties of Zircaloy-4 and stainless use steel (SUS) 316.

\begin{tabular}{ccc}
\hline Physical Properties & Zircaloy-4 & SUS 316 \\
\hline Elastic modulus & $99.3 \mathrm{GPa}$ & $193 \mathrm{GPa}$ \\
Shear modulus & $36.2 \mathrm{GPa}$ & $74-82 \mathrm{GPa}$ \\
Tensile strength & $514 \mathrm{MPa}$ & $580 \mathrm{MPa}$ \\
Thermal expansion coefficient & $6.3 \times 10^{-6} / \mathrm{K}$ & $18.2 \times 10^{-6} / \mathrm{K}$ \\
\hline
\end{tabular}

Table 2. Outer diameters and inner diameters of the metal tubes before and after swaging.

\begin{tabular}{cccc}
\hline Diameter & Zircaloy-4 & SUS 316 & PST \\
\hline Outer diameter $(\mathrm{mm})$ & 9.57 & 11.90 & 11.60 \\
Inner diameter $(\mathrm{mm})$ & 8.30 & 9.82 & 8.08 \\
\hline
\end{tabular}

Thus, SUS 316, which experienced a relatively small plastic deformation, shrank more than Zircaloy-4. It is likely that the residual stress generated at the interface between the metal surface with a low plastic strain (high shrinkage) and the metal surface with a high plastic strain (low shrinkage) caused the two metal surfaces to adhere strongly to each other. In other words, SUS 316, which experienced a high degree of shrinkage, generated compressive stress on the surface of Zircaloy-4, which experienced only a low degree of shrinkage. Meanwhile, tensile stress was generated on the surface of SUS 316. The mechanism of the strong physical adhesion of the tubes, owing to the different residual stresses generated by the shaft tube process, is shown in Figure 7. This mechanism leads to a stable interfacial structure between the metal surfaces, as shown in the cross-sectional SEM image of the tube after swaging (Figure 6). Upon close observation of the interface between the two metals in Figure 6, it is evident that there is a small corrugated interfacial structure. In other words, the compressive stress generated on the surface of Zircaloy- 4 due to the different shrinkage amounts of the two metals caused the Zircaloy-4 surface to shrink again, thereby forming wrinkles on the surface. This corrugated structure may have resulted in the grasping of the surface of SUS 316, which in turn led to the bonding of the two different metals after room temperature condensation. Such strong adhesive interface behavior was well demonstrated with quenching heat treatment experiments after high-temperature exposure, as shown below. 


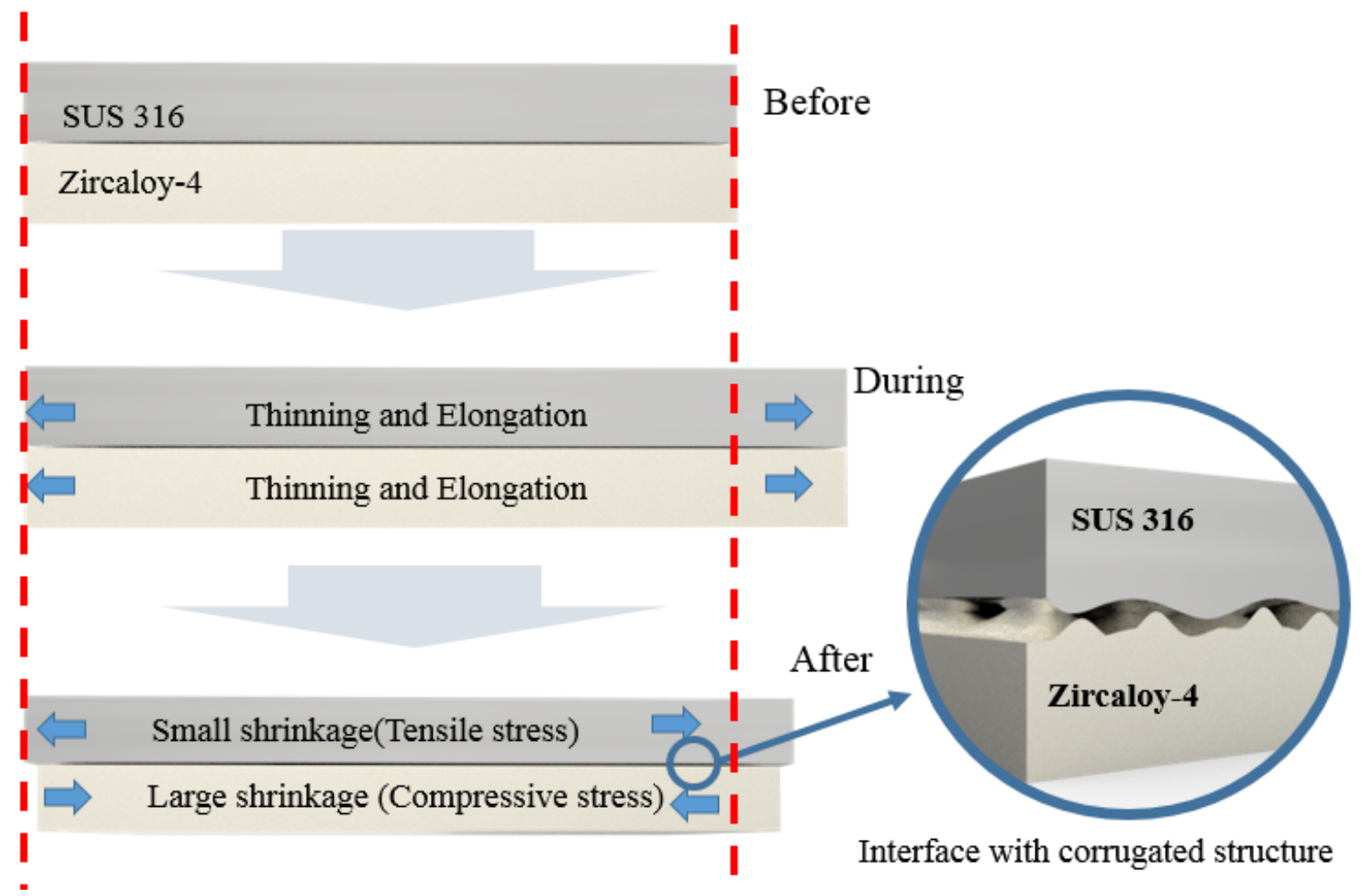

Figure 7. Mechanism for strong physical adhesion of different tubes due to residual stresses generated by the shaft tube process.

To evaluate the thermal stability of the PST fabricated using the room-temperature condensation process, an experiment was performed where the PST underwent rapid cooling after exposure to high temperature under ambient conditions. Figure 8 shows an image of a Zircaloy- 4 tube and a PST quenched to room temperature after being maintained at temperatures of 600,900 , or $1200^{\circ} \mathrm{C}$ for $1 \mathrm{~h}$. The color of the bare Zircaloy-4 cladding changed due to oxidation, even at $600{ }^{\circ} \mathrm{C}$. Under $1200{ }^{\circ} \mathrm{C}$, the PST disintegrated not only due to severe oxidation phenomenon but also experienced external surface peeling [22].

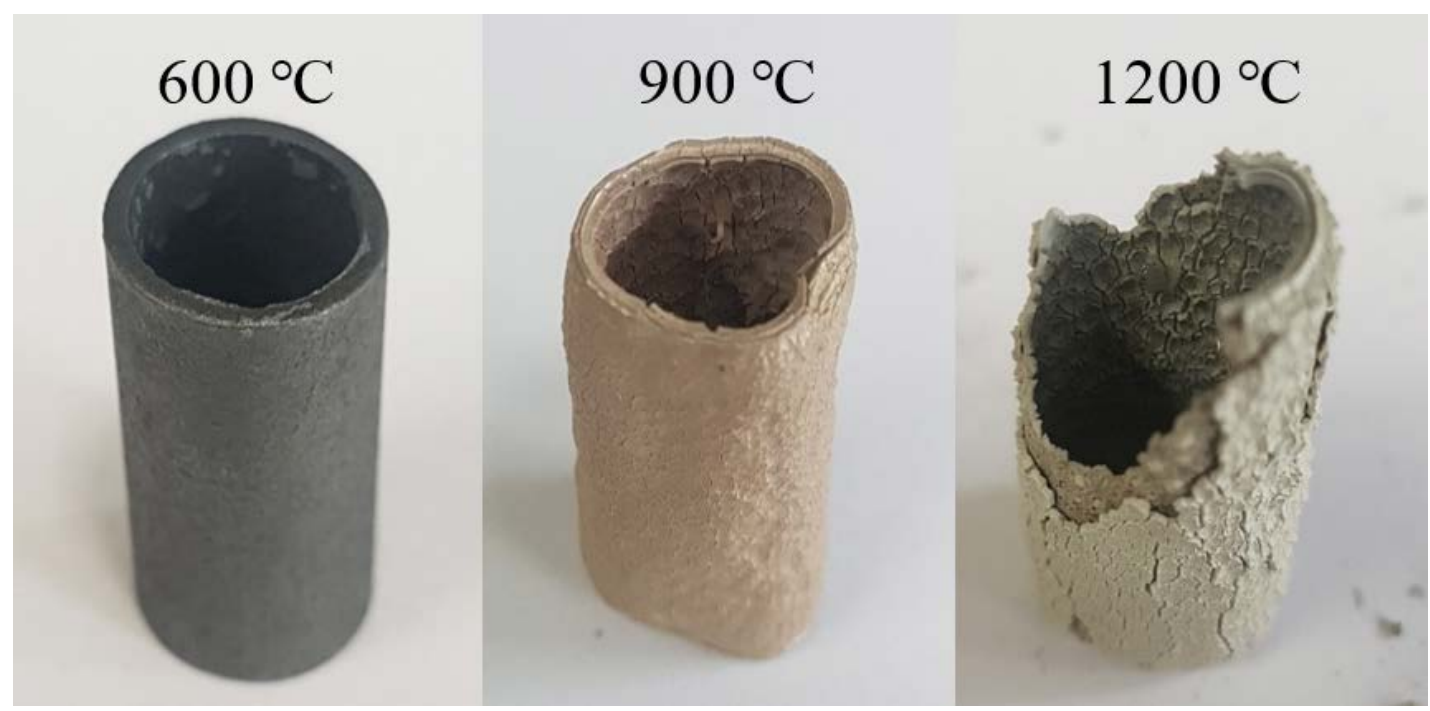

(a)

Figure 8. Cont. 


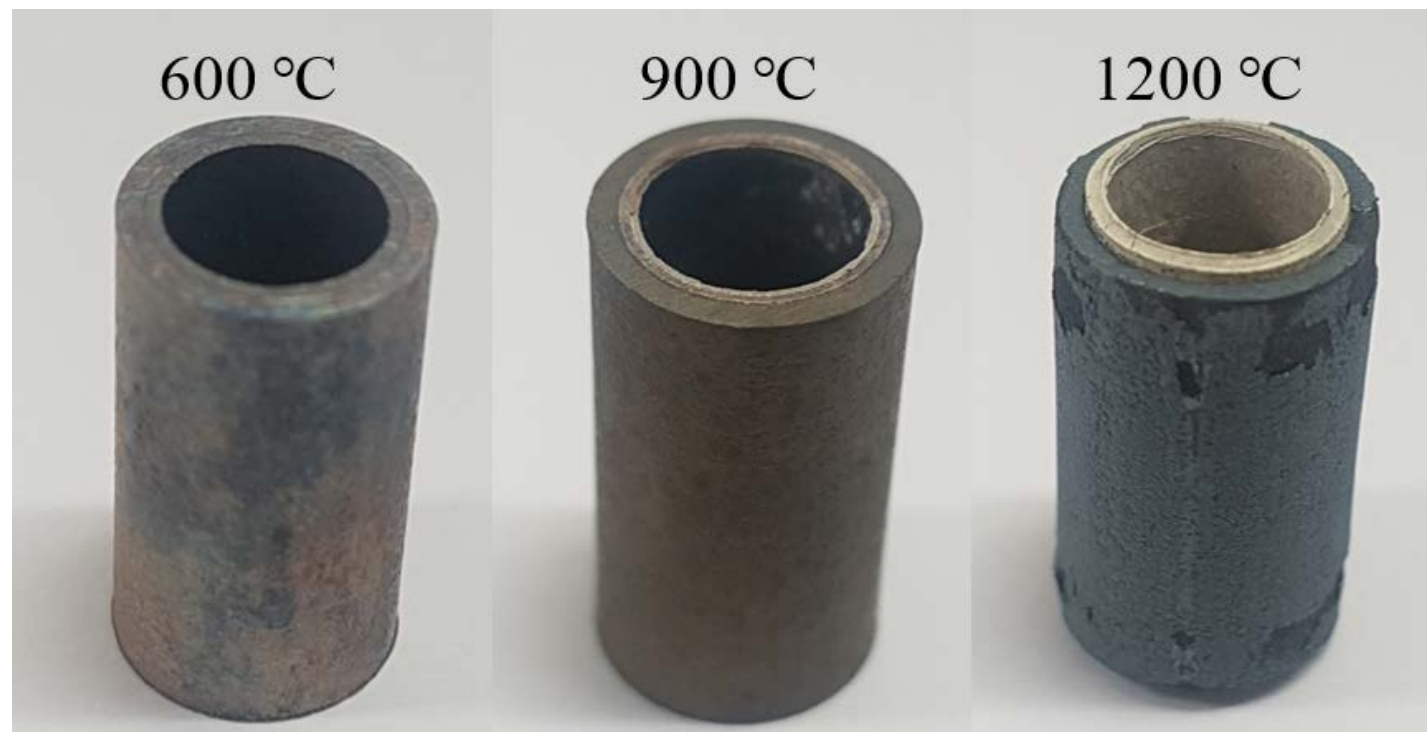

(b)

Figure 8. Appearance after maintaining (a) the Zircaloy-4-only tube and (b) the PST at 600, 900, and $1200{ }^{\circ} \mathrm{C}$ for $1 \mathrm{~h}$.

Noticeably, the structural breakdown of the Zircaloy-4 tube after being exposed to high temperatures is exceedingly similar to the high-temperature disintegration of natural limestone [23]. Thermal shock tests of natural limestone concluded that its oxide layer is formed by an oxidation reaction at high temperatures. As the resulting oxide layer exhibits a large thermal expansion difference compared with the non-oxidized layer inside (owing to the differences in thermal shock received during cooling) and an immensely high amount of thermal stress accumulates at the interface between the oxide layer and the non-oxidized layer, the oxidized surface layer can be peeled off easily. In contrast, for the PST manufactured by the tube process, no surface peeling or structural failure was observed, even after heat treatment at $1200{ }^{\circ} \mathrm{C}$. This is because the external material, SUS 316, which has a higher oxidation resistance than Zircaloy-4, inhibited the oxidation of Zircaloy-4 by preventing oxygen migration to the surface of Zircaloy-4. To observe the interface more clearly, the SEM analysis results of the PST cross-section before and after the heat treatment are shown in Figure 9. No collapse was observed at the interface of the quenched sample after exposure at 600 and $900^{\circ} \mathrm{C}$. In contrast, at $1200^{\circ} \mathrm{C}$, the interface of the quenched sample showed exfoliation and porosity due to volume expansion. It is assumed that this is caused by a large amount of oxygen diffusion from the center of Zircaloy- 4 to the interface between the two metals. However, even when the PST was exposed to $1200{ }^{\circ} \mathrm{C}$, the oxidation reaction of the Zircaloy-4 surface was suppressed, along with subsequent structural collapse.

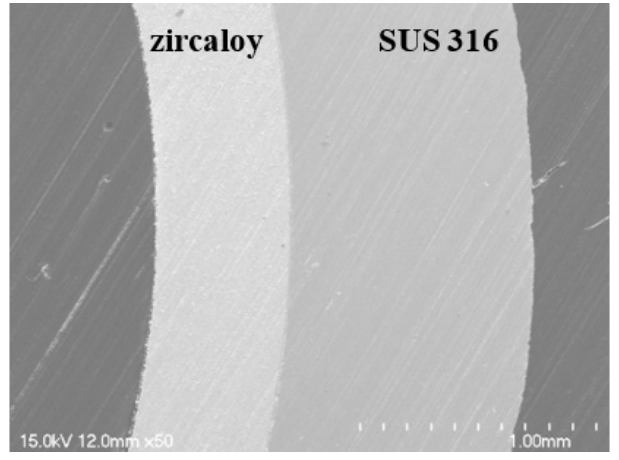

(a) $600{ }^{\circ} \mathrm{C}$

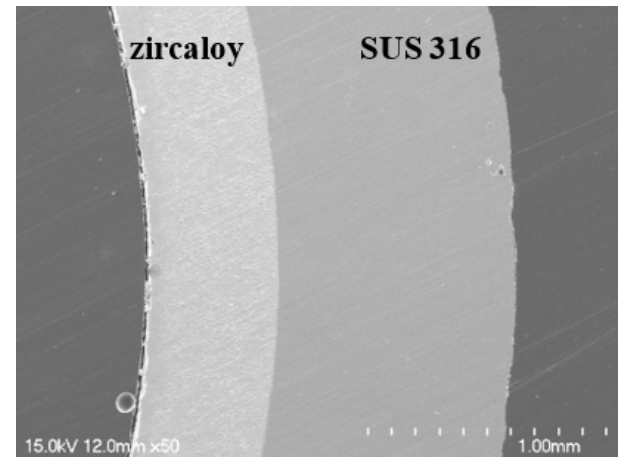

(b) $900{ }^{\circ} \mathrm{C}$

Figure 9. Cont. 


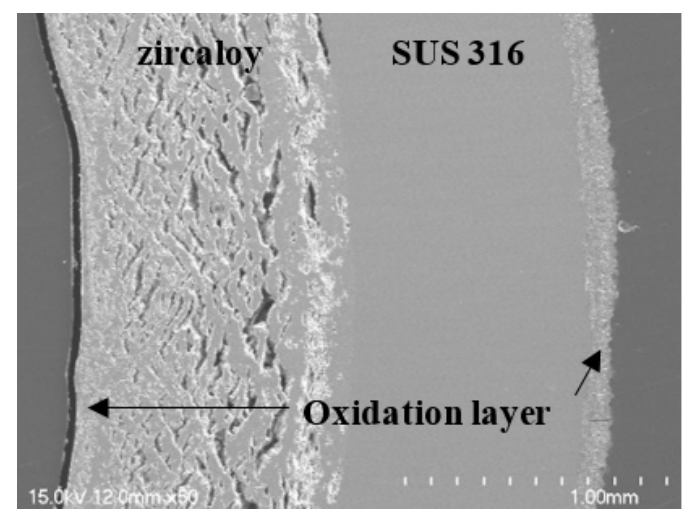

(c) $1200{ }^{\circ} \mathrm{C}$

Figure 9. Scanning electron microscopy (SEM) images of cross-sections of the PST maintained at 600, 900 , and $1200{ }^{\circ} \mathrm{C}$ for $1 \mathrm{~h}$.

To confirm the diffusion behavior of the PST, an EDS analysis was conducted, as shown in Figure 10. After heat treatment at 600 and $900{ }^{\circ} \mathrm{C}$, the diffusion of $\mathrm{Zr}$ did not occur in the SUS 316 direction and no metallic elements of SUS 316 were seen in the Zircaloy-4 direction. Compositional analysis by EDS line scanning showed that the interface between Zircaloy-4 and PST did not degrade even when exposed to high temperatures. However, after heat treatment at $1200{ }^{\circ} \mathrm{C}$, a well-known eutectic reaction caused an interdiffusion reaction, in which an $\mathrm{Fe}-\mathrm{Zr}$ complex with a melting point of $928^{\circ} \mathrm{C}$ was formed [24]. Slight diffusion occurred at $1200^{\circ} \mathrm{C}$ but it still exhibited high stability at operating and accident conditions. These results show that a PST consisting of a metal surface and Zircaloy-4 (e.g., 10Al-90Cr, etc.) [25], and fabricated using the tube process, has the potential to be used as ATF cladding. The interface of the sample, when exposed to $1200{ }^{\circ} \mathrm{C}$, as well $600{ }^{\circ} \mathrm{C}$ and $900{ }^{\circ} \mathrm{C}$, did not appear to peel off easily. From this, it can be concluded that an ATF cladding comprising the PST can maintain stability even at $1200^{\circ} \mathrm{C}$ because the inside of the tube is isolated from external conditions during actual use. TEM analysis was performed to confirm the interfacial stability of the PST after exposure to high temperatures. Figure 11 is a cross-sectional TEM image that shows the interfacial structure of Zircaloy-4/SUS 316 of the PST when quenched to room temperature after being maintained at $900{ }^{\circ} \mathrm{C}$ for $1 \mathrm{~h}$. Rapid cooling to room temperature after exposure to high temperatures is generally well-suited for inducing significant thermal stresses at an interface to observe the physical stability of the interface. Images were obtained at three different magnifications to observe the interfacial condition over a wide range of PST cross-sections and nanoscale. The width of the PST interface was $0.03 \mu \mathrm{m}(30 \mathrm{~nm})$ after heat treatment, as elucidated from the highest-magnification images. Moreover, no new interface was formed between the secondary phase and each tube due to the interdiffusion of the two tube components. This is in good agreement with the results of EDS, shown in Figure 10. Therefore, it is evident that the interface between two different tubes can maintain physicochemical stability, even when the PST formed by swaging is exposed to high temperatures. These results suggest that the development of several m-grade ATF claddings based on Zircaloy-4 is feasible, if conditions such as the type of tube used, its physical shape, and the optimum swaging pressure applied to the tube are established. 


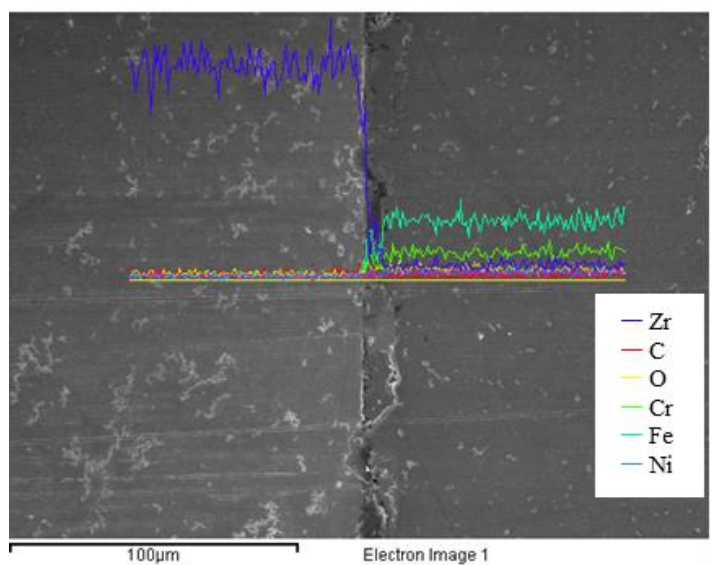

(a) Before heat treatment

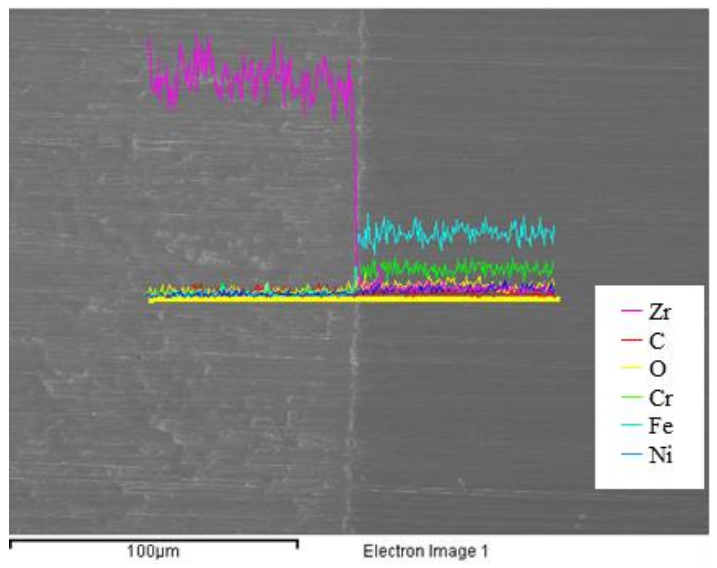

(c) $900{ }^{\circ} \mathrm{C}$ heat treatment

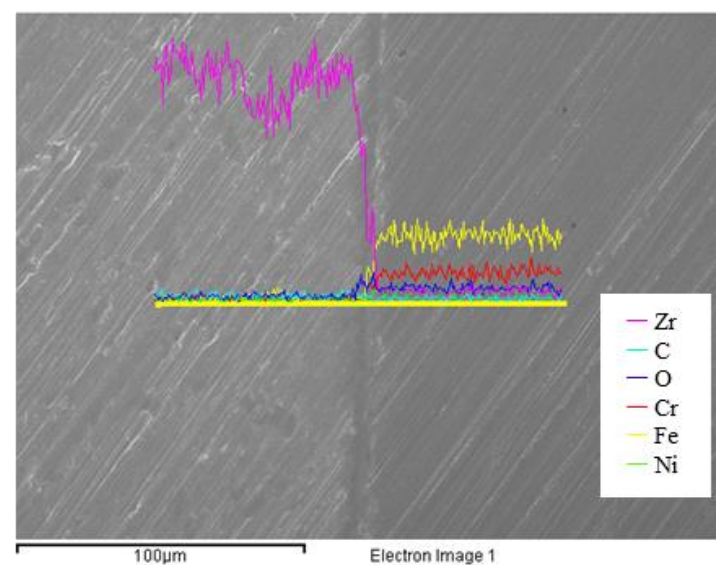

(b) $600^{\circ} \mathrm{C}$ heat treatment

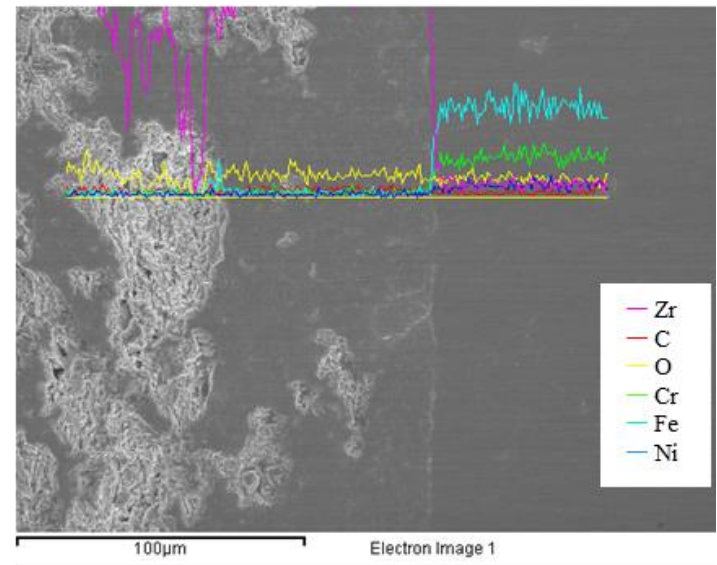

(d) $1200^{\circ} \mathrm{C}$ heat treatment

Figure 10. Energy-dispersive X-ray spectra of the PST before and after heat treatments at 600, 900, and $1200{ }^{\circ} \mathrm{C}$ for $1 \mathrm{~h}$.

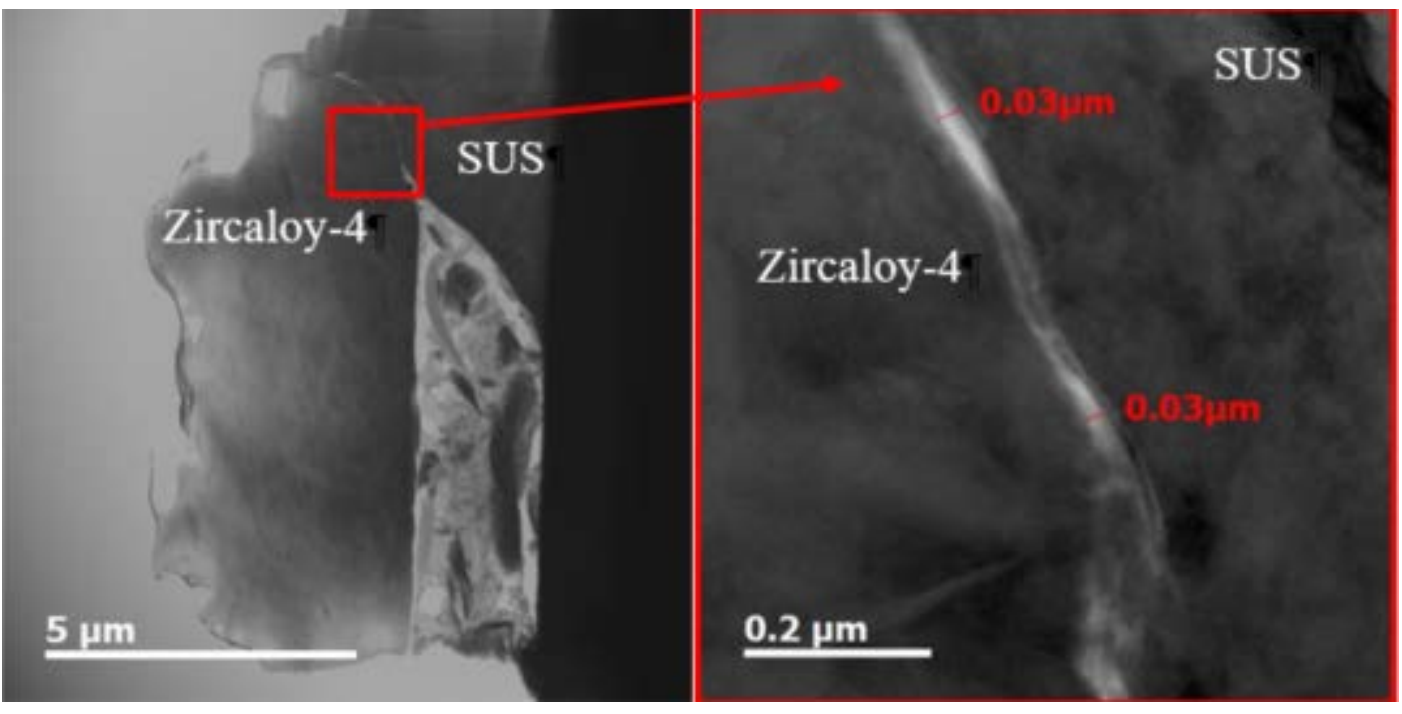

Figure 11. Cross-sectional transmission electron microscopy (TEM) image showing the interfacial structure of the Zircaloy-4/SUS 316 PST quenched to room temperature after being maintained at $900{ }^{\circ} \mathrm{C}$ for $1 \mathrm{~h}$. 
The results show that the tube process has a high potential for the development of an ATF cladding with a length of several meters, based on Zircaloy-4. The results suggest that controlling the compressive stress applied along the axial direction of the tube and the tensile stress occurring in the longitudinal direction will enable the facile and rapid development of ATF claddings, with their geometries calculated according to the design.

\section{Conclusions}

A Zircaloy-4-based PST, over $90 \mathrm{~cm}$ in length, was successfully fabricated using a simple straight tube process that was carried out at room temperature. Zircaloy-4, a material exhibiting well-known physicochemical properties for nuclear power operation, was inserted into a SUS 316 tube. It was possible to fix the SUS 316 tube to the outer surface of Zircaloy-4 by applying compressive stress toward the center of the tube, such that it exhibited strong adhesion. PST cross-sectional observations using OM and SEM revealed no three-dimensional defects, such as gaps or voids, at the interfaces of the two metal tubes. To confirm the high-temperature stability and thermal shock behavior of the PST, it was quenched to room temperature after being kept for $1 \mathrm{~h}$ at 600,900 , and $1200{ }^{\circ} \mathrm{C}$. It was inferred from the OM and SEM analyses that no macroscopic defects were formed at the interface between SUS 316 and the Zircaloy-4 cladding after heat treatment. Even if the prepared PST was maintained at $900^{\circ} \mathrm{C}$, an interdiffusion reaction between the elements constituting Zircaloy-4 and SUS 316 would not occur. The Zircaloy-4-based PST fabricated using a room-temperature condensation process has been found to have highly stable physicochemical properties, even on quenching from high temperatures. Although SUS 316 is not the optimal cladding material, PST using this showed better thermal stability than bare Zircaloy- 4 tube and it was confirmed that the swaging process can be applied to ATF cladding production. In conclusion, if (1) a thin external dissimilar metal tube and (2) a conduit device capable of controlling the compressive stress applied during the condensation process and the tensile stress in the longitudinal direction are used, then ATF claddings, which are widely used in nuclear power plant operations, can easily be manufactured to a length of up to $4 \mathrm{~m}$. In addition, the swaging method described herein is likely to find potential use for a variety of applications, especially in fields where PST structures are crucial, i.e., when specific surface properties and uniform physical properties throughout the tube are critical.

Author Contributions: Conceptualization, Y.S.Y.; methodology, Y.S.Y. and J.H.K.; software, J.H.K.; validation, Y.K. and J.H.K.; formal analysis, D.Y.K. and Y.S.Y.; investigation, D.Y.K. and Y.N.L.; resources, Y.K.; data curation, J.H.K. and Y.K.; writing—original draft preparation, D.Y.K.; writing-review and editing, Y.N.L. and Y.S.Y.; visualization, Y.S.Y.; supervision, Y.K. and Y.S.Y.; project administration, Y.S.Y.; funding acquisition, Y.K. All authors have read and agreed to the published version of the manuscript.

Funding: This research was funded by Engineering Research Center of Excellence Program of Korea Ministry of Science, ICT and Future Planning (MSIP)/National Research Foundation of Korea (NRF) grant number NRF-2008-0062609 and was funded by Korea Hydro and Nuclear Power Co. Ltd. (KHNP) grant number No. 2018-safety-10.

Acknowledgments: This work was supported by the Engineering Research Center of Excellence Program of Korea Ministry of Science, ICT and Future Planning (MSIP)/National Research Foundation of Korea (NRF) (Grant NRF-2008-0062609). This work was also supported by Korea Hydro and Nuclear Power Co. Ltd. (No. 2018-safety-10).

Conflicts of Interest: The authors declare no conflict of interest.

\section{References}

1. Carmack, J.; Goldner, F.; Bragg-Sitton, S.M.; Snead, L.L. Overview of the US DOE Accident Tolerant Fuel Development Program; Idaho National Laboratory: Idaho Falls, ID, USA, 2013.

2. Cheng, B.; Kim, Y.J.; Chou, P.; Deshon, J. Development of Mo-alloy for LWR fuel cladding to enhance fuel tolerance to severe accidents. Top Fuel 2013, 2013, 15-19. 
3. Idarraga-Trujillo, I.; Le Flem, M.; Brachet, J.C.; Le Saux, M.; Hamon, D.; Muller, S.; Vandenberghe, V.; Tupin, M.; Papin, E.; Monsifrot, E.; et al. Assessment at CEA of coated nuclear fuel cladding for LWRs with increased margins in LOCA and beyond LOCA conditions. Top Fuel 2013, 2, 15-19.

4. Kim, H.G.; Kim, I.H.; Park, J.Y.; Koo, Y.H. Application of Coating Technology on Zirconium-Based Alloy to Decrease High-Temperature Oxidation. Zircon. Nucl. Ind. 2015, 465, 346-369.

5. Bischoff, J.; Delafoy, C.; Vauglin, C.; Barberis, P.; Roubeyrie, C.; Perche, D.; Duthoo, D.; Schuster, F.; Brachet, J.C.; Schweitzer, E.W.; et al. AREVA NP's enhanced accident-tolerant fuel developments: Focus on Cr-coated M5 cladding. Nucl. Eng. Technol. 2018, 50, 223-228. [CrossRef]

6. Thompson, T.; Zachary, A.; Kurt, T.; Yukinori, Y. Elastic Modulus Measurement of ORNL ATF FeCrAl Alloys. Ornl/Tm 2015, 632, 1-17.

7. Wu, X.; Kozlowski, T.; Hales, J.D. Neutronics and fuel performance evaluation of accident tolerant FeCrAl cladding under normal operation conditions. Ann. Nucl. Energy 2015, 85, 763-775. [CrossRef]

8. Petrie, C.M.; Koyanagi, T.; McDuffe, J.L.; Deck, C.P.; Katoh, Y.; Terrani, K.A. Experimental design and analysis for irradiation of $\mathrm{SiC} / \mathrm{SiC}$ composite tubes under a prototypic high heat flux. J. Nucl. Mater. 2017, 491, 94-104. [CrossRef]

9. Kim, H.G.; Kim, I.H.; Jung, Y.I.; Park, D.J.; Park, J.Y.; Koo, Y.H. Adhesion property and high-temperature oxidation behavior of Cr-coated Zircaloy-4 cladding tube prepared by 3D laser coating. J. Nucl. Mater. 2015, 465, 531-539. [CrossRef]

10. Bischoff, J.; Delafoy, C.; Chaari, N.; Vauglin, C.; Buchanan, K.; Barberis, P.; Monsifrot, E.; Schuster, F.; Brachet, J.C.; Nimishakavi, K. CR-coated cladding development at framatome. Top Fuel 2018, 2018, A0152.

11. Dryepondt, S.; Unocic, K.A.; Hoelzer, D.T.; Massey, C.P.; Pint, B.A. Development of low-Cr ODS FeCrAl alloys for accident-tolerant fuel cladding. J. Nucl. Mater. 2018, 501, 59-71. [CrossRef]

12. Rebak, R.B.; Gassmann, W.P.; Terrani, K.A. Managing nuclear power plant safety with FeCrAl alloy fuel cladding. In Top Safe 2017; IAEA Safety in Reactor Operation: Vienna, Austria, 2017.

13. Kim, D.; Ko, M.; Lee, H.G.; Park, J.Y.; Kim, W.J. Influence of Winding Patterns and Infiltration Parameters on Chemical Vapor Infiltration Behaviors of SiCf/SiC Composites. J. Korean Ceram. 2014, 51, 453. [CrossRef]

14. Kim, J.Y.; Oh, J.Y.; Lee, T.I. Multi-dimensional nanocomposites for stretchable thermoelectric applications. Appl. Phys. Lett. 2019, 114, 043902. [CrossRef]

15. Lee, J.S.; Shin, D.H.; Jang, J. Polypyrrole-coated manganese dioxide with multiscale architectures for ultrahigh capacity energy storage. Energy Environ. Sci. 2015, 8, 3030-3039. [CrossRef]

16. Kim, D.; Kim, J.; Lee, J.; Kang, M.K.; Kim, S.; Park, S.H.; Kim, J.; Choa, Y.H.; Lim, J.H. Enhanced Magnetic Properties of FeCo Alloys by Two-Step Electroless Plating. J. Electrochem. Soc. 2019, 166, D131-D136. [CrossRef]

17. Ferrer-Argemi, L.; Yu, Z.; Kim, J.; Myung, N.V.; Lim, J.H.; Lee, J. Silver content dependent thermal conductivity and thermoelectric properties of electrodeposited antimony telluride thin films. Sci. Rep. 2019, 9, 1-8. [CrossRef]

18. Nam, H.; Kim, H.S.; Han, J.H.; Kwon, S.J.; Cho, E.S. A Study on the Formation of 2-Dimensional Tungsten Disulfide Thin Films on Sapphire Substrate by Sputtering and High Temperature Rapid Thermal Processing. J. Nanosci. Nanotechnol. 2018, 18, 6257-6264. [CrossRef] [PubMed]

19. Giggins, C.S.; Pettit, F.S. Corrosion of metals and alloys in mixed gas environments at elevated temperatures. Oxid. Met. 1980, 14, 363-413. [CrossRef]

20. Hofmann, P.; Markiewicz, M. Chemical interactions between as-received and pre-oxidized Zircaloy-4 and stainless steel at high temperatures, No. KFK-5106. Kernforschungszentrum Karlsruhe GmbH (Germany). Proj. Nukl. Sicherh. 1994, 26,1-41.

21. Wu, H.Y.; Lee, S.; Wang, J.Y. Solid-state bonding of iron-based alloys, steel-brass, and aluminum alloys. J. Mater. Process. Technol. 1998, 75, 173-179. [CrossRef]

22. Kim, H.H.; Kim, J.H.; Moon, J.Y.; Lee, H.S.; Kim, J.J.; Chai, Y.S. High-temperature oxidation behavior of Zircaloy-4 and Zirlo in steam ambient. J. Mater. Sci. Technol. 2010, 26, 827-832. [CrossRef]

23. Becattini, V.; Motmans, T.; Zappone, A.; Madonna, C.; Haselbacher, A.; Steinfeld, A. Experimental investigation of the thermal and mechanical stability of rocks for high-temperature thermal-energy storage. Appl. Energy 2017, 203, 373-389. [CrossRef] 
24. Kim, J.H.; Choi, B.K.; Baek, J.H.; Jeong, Y.H. Effects of oxide and hydrogen on the behavior of Zircaloy-4 cladding during the loss of the coolant accident (LOCA). Nucl. Eng. Des. 2006, 236, 2386-2393. [CrossRef]

25. Kim, J.M.; Ha, T.H.; Kim, I.H.; Kim, H.G. Microstructure and oxidation behavior of CrAl laser-coated Zircaloy-4 alloy. Metals 2017, 7, 59. [CrossRef]

(C) 2020 by the authors. Licensee MDPI, Basel, Switzerland. This article is an open access article distributed under the terms and conditions of the Creative Commons Attribution (CC BY) license (http://creativecommons.org/licenses/by/4.0/). 